\title{
ILTMA. CORTE DE APELACIONES DE PUERTO MONTT. RECURSO DE NULIDAD POR INFRACCIÓN DE LA GARANTÍA DEL DEBIDO PROCESO. ACOGIDO. ROL Nº $82-2010$
}

\begin{abstract}
RESUMEN: Infringe la garantía del debido proceso -art. $19 \mathrm{~N} .^{\circ} 3$, inciso quinto, CPR- el juez a quo que habiendo admitido a tramitación una denuncia de tutela laboral sin los antecedentes que exige el art. $490 \mathrm{CT}$, aplica sorpresivamente en la sentencia la prueba de indicios del art. $493 \mathrm{CT}$, para dar por acreditada la vulneración de derechos fundamentales. Como consecuencia de lo anterior, la parte denunciada no estuvo en condiciones de explicar los fundamentos de las medidas adoptadas y su proporcionalidad, por lo que fue privada de su derecho a la debida defensa.
\end{abstract}

\section{CONSIDERANDO}

PRIMERO. Que la primera causal de nulidad invocada consiste en la vulneración del artículo 19 No 3 inciso quinto de la Constitución Política de la República, al no fundarse la sentencia en un proceso previo legalmente tramitado con relación a lo señalado en los artículos 490 y 493 del Código del Trabajo, derivando las infracciones legales al proceso de la transgresión al artículo 490 del Código del Trabajo, al admitir la denuncia a tramitación sin previo acompañamiento de "todos los antecedentes en los que se fundamente", aplicando solo en la sentencia la norma del artículo 493 del Código del Trabajo, impidiendo de esa forma a su parte "explicar los fundamento, de las medidas adoptadas y de su proporcionalidad".

SEGUNDO. Que conforme dan cuenta los antecedentes tenidos a la vista, doña Gloria Alejandra Torres Mansilla interpuso denuncia por vulneración de derechos fundamentales en contra de Empresa Portuaria Puerto Montt, ello de conformidad con lo dispuesto en los artículos 485 y siguientes del Código del Trabajo y artículo $19 \mathrm{~N}^{\circ} 1$ de la Constitución Política de la República, solicitando sea acoja y se declare que la empresa denunciada vulneró la garantía constitucional antes mencionada ordenándosele cancelar las sumas demandadas por los conceptos que indica, denuncia que fue acogida, declarándose en consecuencia la existencia de una vulneración de la garantía constitucional establecida en el artículo $19 \mathrm{~N}^{\circ} 1$ de la Constitución Política del Estado, la que se produjo con ocasión del despido, por lo que condena a la denunciada al pago de las prestaciones indicadas en la sentencia que se recurre por vía de nulidad.

Tercero. Que el artículo 490 del Código del Trabajo dispone que "la denuncia deberá contener, además de los requisitos generales que establece el artículo 466, la enunciación clara y precisa de los hechos constitutivos de la vulneración alegada acompañándose todos los antecedentes en los que se fundamente. En caso que no los contenga, se concederá un plazo fatal de cinco días para su incorporación."

Por su parte el artículo 493 del Código del Trabajo establece que: "Cuando de los antecedentes aportados por la parte denunciante resulten indicios suficientes de que se ha producido la vulneración de derechos fundamentales, corresponderá al denunciado explicar los fundamentos de las medidas adoptadas y de su proporcionalidad". 
Que una interpretación armónica de disposiciones legales antes referidas permite concluir que los antecedentes a que se refiere el artículo 493 del Código del Trabajo son aquellos ordenados acompañar por el artículo 490 del mismo Cuerpo Legal.

CUARTO. Que como ya se dijo, una interpretación armónica de las disposiciones legales antes referidas permite concluir que los antecedentes a que se refiere el artículo 493 del Código del Trabajo son aquellos ordenados acompañar por el artículo 490, de modo tal que, su ponderación permitirá al Juez advertir al empleador sobre el particular, permitiéndole producir prueba en tal sentido, a fin de explicar los fundamentos de las medidas adoptadas y de su proporcionalidad, lo que no ocurrió en el caso que nos ocupa.

Claro está que la norma en comento -artículo 490 del Código del Trabajo- no exime a la parte denunciante de su obligación de aportar los antecedentes que constituyan el fundamento de su acción, más aún cuando dispone para el caso que a la denuncia no se hayan acompañados dichos antecedente, se concederá un plazo fatal de cinco días para incorporarlos. Otro no puede ser el sentido de la norma dadas las características especialísimas del procedimiento de Tutela de Laboral y teniendo además en consideración que la norma del artículo 493 del mismo estatuto jurídico solo exige para su procedencia que de los antecedentes aportados por la parte denunciante resulten indicios suficientes de que se haya producido la vulneración de derechos constitucionales.

La norma del artículo 493 del Código del Trabajo, no establece inversión de la carga probatoria, por cuanto, dado los términos de la misma, no es suficiente que se alegue una vulneración de derechos fundamentales para que se traslade al empleador la carga probatoria, la víctima o denunciante debe acreditar al menos la existencia de "indicios suficientes" de la existencia de la conducta lesiva, caso en el cual nace para el demandado el deber probar que su conducta se debió a motivos objetivos y razonables.

Así y solo ante la aportación de los indicios suficientes, acompañados por la denunciante, el empleador tiene la opción como señala el mismo artículo 493 del Código del Trabajo, de "explicar los fundamentos de las medidas adoptadas y de su proporcionalidad".

QUINTO. En el caso en análisis y conforme se puede constatar de los antecedentes tenidos a la vista, la denunciante no acompañó a su denuncia los antecedentes en que fundamentaba la supuesta vulneración de derechos fundamentales, incumpliéndose la norma del artículo 490 del Código del Trabajo, más aún cuando, no obstante haber sido advertida dicha omisión por parte de la denunciada al oponer excepción dilatoria, esta fue rechazada.

Por lo demás y pese a no contenerlos, no fijó plazo alguno, como lo ordena perentoriamente el incido final de la norma antes citada, aplicando la prueba indiciaria o indicios recién en la sentencia definitiva, como consta de su considerando catorce.

SEXTO. Confirma la ausencia de antecedentes acompañados a la denuncia, y como consecuencia de ellos la ausencia de indicios, la fijación por parte del tribunal del siguiente punto de prueba: "Si la denunciante fue objeto de una persecución laboral y hostigamiento por parte de tres funcionarios de la empresa denunciada, la que fue aumentando en forma progresiva y persistente, degradándola profesional y humanamente, quitándole funciones al interior de la empresa, creando en su interior un ambiente hostil en su contra con el propósito de obtener su renuncia o despido el que se produjo el 16 de noviembre de 2009. En su caso efectos provocados en la denunciante". 
Así las cosas, claramente se constata del punto de prueba fijado por el tribunal, que este no contaba con los indicios suficientes de que se haya producido la vulneración denunciada, por lo que estimó necesario recibir a prueba tal circunstancia. Es más de la propia redacción del mismo se constata que no liberó a la denunciante de probar tal hecho.

SÉPTIMO. Que de esta forma se ha incurrido en la infracción de garantía impetrada por la recurrente, por cuanto y como se advierte del considerando catorce y quince de la sentencia en revisión el juez a quo al momento de resolver el asunto sometido a su decisión "sorpresivamente" aplica "indicios" para tener por acreditada la vulneración de la garantía constitucional del artículo $19 \mathrm{~N}^{\circ} 1$ de la Constitución Política del Estado, con ocasión del despido, pudiendo recién en este momento enterarse de aquello, privándolo del derecho que le asiste a ofrecer y rendir las probanzas tendientes a desvirtuar la denuncia formulada en su contra, explicar los fundamentos de las medidas adoptadas y de su proporcionalidad, tal como lo dispone en forma imperativa el artículo 493 del Código del Trabajo, lo que no ocurrió en el caso de autos, vulnerándose en consecuencia la garantía constitucional del artículo $19 \mathrm{~N}^{\circ} 3$ inciso $5^{\circ}$ de la Constitución Política del Estado, esto es la garantía del debido proceso, privándola de su derecho a la debida defensa, por cuanto no estuvo en condiciones de "explicar los fundamentos de las medidas adoptadas y de su proporcionalidad", lo cual influyó en lo dispositivo del fallo.

OCTAVO. Que así y no obstante lo anterior, al razonar el sentenciador en su considerando catorce y quince que tiene plena aplicabilidad el artículo 493 del Código del Trabajo resulta contradictorio con lo resuelto por él mismo al recibir la causa a prueba en los términos expuestos en el considerando sexto precedente, vulnerando en consecuencia la garantía del debido proceso en su estándar del derecho a prueba y derecho a defensa, por lo que corresponde acoger la nulidad por esta causal y así se declarará.

Es así como en el considerando en comento refiere "Que cabe señalar que una de las principales novedades introducidas en el nuevo procedimiento de tutela de derecho laboral, lo es la institución de la "prueba indiciaria" que opera como una verdadera garantía sobre el onus probandi, de modo que lo facilita en el ámbito en donde la posibilidad de allegar prueba resulta difícil para el trabajador afectado debido normalmente al ocultamiento de la verdadera causa vulneratoria. En efecto el artículo 493 del Código del Trabajo señala que "cuando de los antecedentes aportados por la parte denunciante resulten indicios suficientes de que se ha producido la vulneración corresponderá al denunciado explicar los fundamentos de las medidas adoptadas y de su proporcionalidad" de manera que se produce un aligeramiento en la carga de la prueba por parte del trabajador de manera que es estándar probatorio que debe exigírsele es que aporte indicios suficientes de que se ha producido la vulneración...", indicios que no aportó en la oportunidad que correspondía hacerlo impidiéndole de esta forma ejercer su derecho de defensa a la parte denunciada sin haber podido esta explicar los fundamentos de las medidas adoptadas y de su proporcionalidad, aplicando en definitiva los indicios en la sentencia misma, enterándose recién de ello la denunciada al momento de tomar conocimiento del contenido de la misma, produciéndose en consecuencia la infracción de garantía invocada por lo que procede acoger el recurso de nulidad impetrado por la causal en comento y como consecuencia de ello anular la sentencia dictada en estos antecedentes y así se declarará, al no existir indicios suficientes de que se hubiera 
producido la vulneración de derechos fundamentales que invocó la denunciante, por lo que se anulará la sentencia definitiva recurrida.

NOVENO. Que, conforme lo resuelto precedentemente se omite pronunciamiento en relación a las demás causales invocadas por la recurrente, por resultar ello innecesario.

DÉCIMO. Que conforme lo resuelto precedentemente y habiéndose deducido en subsidio demanda por despido injustificado procede pronunciarse a su respecto, conforme se dirá.

Con lo expuesto, disposiciones legales citadas y lo dispuesto en los artículos 477 y 482 del Código del Trabajo, se declaŕa:

Que se ACOGE el recurso de nulidad interpuesto por don RODRIGO KAUAK ! MANSURATI, en representación de EMPRESA PORTUARIA PUERTO MONTT, en contra de la sentencia definitiva dictada con fecha 16 de abril de 2010 , invalidándose en consecuencia la sentencia definitiva dictada con fecha dieciséis de abril de dos mil diez por el juez del Trabajo don Moisés Montiel, la que se reemplaza por la que se dictará a continuación.

Regístrese y devuélvase.

Redacción de la Ministro Suplente doña Patricia Miranda Alvarado.

Pronunciada por el Ministro Titular don Hernán Crisosto Greisse, Ministra Suplente doña Patricia Miranda Alvarado y Fiscal Judicial Titular doña Mirta Zurita Gajardo.

No firma la Ministra Suplente doña Patricia Miranda Alvarado no obstante haber concurrido a la vista, estudio y acuerdo de estos antecedentes por haber cesado en su cometido funcionario. 